\title{
Disparities in Health Insurance Coverage and Health Status Among Farmworkers, Sonoma County, California, 2013-2014
}

Kristin L. Moore, MPH; Jenny Mercado, MPH; Jana Hill, MPH; Sarah C. Katz, MPH

\begin{abstract}
Suggested citation for this article: Moore KL, Mercado J, Hill J, Katz SC. Disparities in Health Insurance Coverage and Health Status Among Farmworkers, Sonoma County, California, 2013-2014. Prev Chronic Dis 2016;13:150519. DOI: http:// dx.doi.org/10.5888/pcd13.150519.
\end{abstract}

\section{PEER REVIEWED}

\section{Abstract}

\section{Introduction}

The Sonoma County Farmworker Health Survey (FHS) was conducted to describe the health and well-being of adult farmworkers in Sonoma County, California, and to identify preventable health disparities for this population.

\section{Methods}

From September 2013 through January 2014, venue-based and convenience sampling were used to survey 293 farmworkers aged 18 years or older. The questions included self-rated general health, diabetes and hypertension, and body mass index. To identify disparities between surveyed farmworkers and Sonoma County residents overall, age-adjusted prevalence estimates were developed by using indirect standardization to the adult ( $\geq 18$ years) Sonoma County sample from the California Health Interview Survey for 2011-2012.

\section{Results}

Surveyed farmworkers were mostly male (91\%) and Latino or Hispanic $(95 \%)$, and $54 \%$ had an educational attainment of 8 th grade or less. Most (81\%) farmworkers reported their families earned less than $\$ 30,000$ in 2012. After adjusting for age, 30\% of farmworkers had US-based health insurance as compared with the $86 \%$ of Sonoma County adults in $2011-2012(P<.001)$, and $15 \%$ of farmworkers reported ever being diagnosed with diabetes after adjusting for age as compared with $5 \%$ of Sonoma County adults $(P=.002)$. After adjusting for age, $44 \%$ of farmworkers reported poor or fair health in general as compared with $13 \%$ of Sonoma County adults $(P<.001)$.

\section{Conclusion}

We identified significant health disparities between Sonoma County farmworkers and Sonoma County adults overall. Additional research and new health policies are necessary to eliminate these health disparities and to facilitate farmworker access to the health care system.

\section{Introduction}

Significant differences in health outcomes, particularly among individuals in different racial, ethnic, and socioeconomic groups, have been widely acknowledged $(1,2)$. These health disparities among minority populations account for higher premature death and infant mortality rates, higher disease burden, and poorer access to health care when compared with the US national average (3). As the United States continues to experience major demographic shifts, health disparities and their causal conditions must be reduced or eliminated if the country is to continue health improvements. Reducing disparities has been prioritized by the US Surgeon General, the Institute of Medicine, the Centers for Disease Control and Prevention (CDC), and other leading health and public health agencies $(1,4)$.

The 1999 California Agricultural Workers Health Survey (CAWHS) was a study of farmworker health in California. The study found that California farmworkers were mostly Hispanic/ Latino men and undocumented immigrants and had poor access to medical care. Nearly $20 \%$ of male farmworkers had at least 2 major risk factors (high serum cholesterol, high blood pressure, or obesity) for chronic disease (5). This research highlights a minority population that has poor access to health care and health outcomes. However, these data were not compared with the overall California population or with the California immigrant population to better understand disparities in health behaviors and health outcomes. 
In Sonoma County, California, agriculture is a major contributor to the local economy, and agricultural land use accounts for over $60 \%$ of the county's acreage. A healthy agricultural workforce is critical to maintaining the local economy; yet, before our study no data on the health and well-being of local farmworkers were available. To bridge this gap, the Sonoma County Farmworker Health Survey (FHS) was developed with the primary goal of describing the health and well-being of adult farmworkers in Sonoma County and identifying preventable health and wellness disparities. On the basis of prior state and national research, we hypothesized that Sonoma County farmworkers would have less health care access and greater chronic disease prevalence than the general adult Sonoma County population.

\section{Methods}

The FHS was a cross-sectional study of farmworkers in Sonoma County, California, conducted from September 2013 through January 2014. Farmworkers that spoke either English or Spanish, were 18 years of age or older, and had completed any farm work in the preceding 12 months were eligible to participate. A key objective of this study was to describe access to health care and the prevalence of preventable health conditions. To achieve this goal, sample size calculations were based on research examining health insurance status, high blood pressure, and obesity among farmworkers in California (5). Venue-based and convenience sampling were used to survey farmworkers from September 2013 through January 2014. Venue-based sampling was conducted at key sites where farmworkers were located, including day labor centers, community health clinics, and farms throughout Sonoma County. Among the 29 venues approached to participate, 18 (62\% participation rate) agreed to allow data collection. Of the 11 venues that declined to participate, 3 sites were dairies, 4 were farms growing grapes for wine, 2 were other types of farms, and 2 were labor management companies.

The FHS instrument included 130 questions related to health and well-being. For data in this report, we used valid and reliable questions from the California Health Interview Survey (CHIS), a California state-wide survey of health and health care needs (6). To determine self-rated health status, participants in both CHIS and FHS were asked, "Would you say that in general your health is excellent, very good, good, fair, or poor?" Participants were also asked if a doctor had ever diagnosed them with diabetes or high blood pressure, and they were asked if they had US-based health insurance. Participants were asked about their height without shoes and weight when not pregnant to calculate body mass index (BMI). BMIs of 25.0 or more were categorized as overweight or obese, consistent with CDC guidelines (7). Data on demographic variables associated with social determinants of health were col- lected, including data on sex, ethnicity, income, educational attainment, English speaking ability, and family structure. Farmworkers were not asked about their immigration status in the United States. Participants were also asked to self-define if they were farmworkers full-time, part-time, or seasonally and the type of crop at their current or previous farm work job during the previous 12 months.

The FHS survey instrument was available in English and Spanish. From September 2013 through January 2014, 300 farmworkers were surveyed. The survey was administered in-person by trained bilingual and bicultural interviewers. All interview participants were given a \$10 gift card and a packet with local health care and other resources on completion of the interview. This protocol was approved by Western Institutional Review Board.

Data for 7 farmworkers were excluded because of missing or unreliable responses; analyses were conducted on responses from 293 farmworkers using SAS statistical software (SAS Institute Inc). Descriptive statistics were calculated to describe the study population. To identify health disparities between surveyed farmworkers and Sonoma County residents overall, age-adjusted prevalence estimates were developed using indirect standardization to the adult ( $\geq 18$ years) Sonoma County sample from the CHIS for 2011-2012. Age-adjusted estimates included prevalence estimates, 95\% confidence intervals (CIs), and $P$ values. The relationship between self-reported health status and diabetes, high blood pressure, and obesity was assessed to determine if poor or fair health in general was correlated with poorer self-reported health outcomes among farmworkers. Bivariate statistics were calculated using $\chi^{2}$ tests. Multivariable regression models were not developed because of a lack of statistical power. Significance was set at $P<$ .05 .

\section{Results}

Of the 293 farmworkers surveyed, most (91.1\%) were male, Latino or Hispanic (95.4\%), and of Mexican (89.9\%) ancestry (Table 1). Most (68.6\%) farmworkers were aged 18 to 44 years (median, 37 years). Educational attainment among farmworkers was low, with $54 \%$ of farmworkers having an educational attainment of 8th grade or less. Of 182 farmworkers who remembered and reported their total family income in 2012, $148(81.3 \%)$ reported earning less than $\$ 30,000$. Three-quarters of farmworkers were linguistically isolated, with $73.0 \%$ reporting speaking English not at all or a little. Of those reporting family structure, $43.3 \%$ of farmworkers reported being married or living with a partner and children, $32.5 \%$ reported being single, and $24.2 \%$ were married or living with a partner. Nearly all $(88.3 \%)$ of surveyed farmworkers considered Sonoma County their permanent residence, and 91.5\% reported wine grapes as the primary crop in their current or most

The opinions expressed by authors contributing to this journal do not necessarily reflect the opinions of the U.S. Department of Health and Human Services, the Public Health Service, the Centers for Disease Control and Prevention, or the authors' affiliated institutions. 
recent agricultural position. Farmworkers reported being full-time farmworkers who worked for the owner or grower (42.1\%), being full-time farmworkers who worked for a contractor or a labor management company or not knowing who their boss was $(32.5 \%)$, or being part-time or seasonal farmworkers $(25.3 \%)$.

After adjusting for age, $29.6 \%$ of farmworkers had US-based health insurance as compared with $85.7 \%$ of Sonoma County adults who had health insurance $(P<.001)$ (Table 2). Farmworkers with US-based health insurance were significantly more likely to be female $(P=.003)$, married or living with their partner and children $(P=.03)$, and to have higher educational attainment $(P=$ .048 ) (Table 3). Although not significant at $P<.05$, farmworkers doing farm work full-time where their current or previous boss was the owner or grower were more likely than other farmworkers to have US-based health insurance $(P=.07)$. Also, although not significant at $P<.05$, farmworkers aged 25 to 34 years were less likely to have US-based health insurance than those in other age groups $(P=.06)$ (Table 3$)$.

No disparity in age-adjusted prevalence of high blood pressure diagnoses between farmworkers and Sonoma County adults (26.0\% and $24.8 \%$, respectively) was found. After adjusting for age, $14.5 \%$ of farmworkers reported ever being diagnosed with diabetes as compared with $5.2 \%$ of Sonoma County adults $(P=$ .002 ). After adjusting for age, $93.8 \%$ of farmworkers were categorized as overweight or obese as compared with $54.3 \%$ of Sonoma County adults $(P<.001)$ (Table 2$)$. However, BMI data were missing for $21 \%$ of farmworkers, so results should be interpreted with caution.

After adjusting for age, $43.9 \%$ of farmworkers reported poor or fair health in general as compared with $13.1 \%$ of Sonoma County adults $(P<.001)$ (Table 2). Farmworker age was significantly associated with self-reported health status. Farmworkers 55 years or older were the most likely to report poor or fair health in general $(P=.002)$ (Table 3$)$. Farmworker sex, total family income in 2012 , and family structure were not associated with self-reported health status. Farmworkers ever diagnosed with diabetes were significantly more likely to report poor or fair health in general when compared with farmworkers without diabetes $(P=.001)$. Similarly, farmworkers ever diagnosed with high blood pressure were significantly more likely to report poor or fair health in general when compared with farmworkers never diagnosed with high blood pressure $(P<.001)$ (Table 3$)$.

\section{Discussion}

To our knowledge, this is the first study identifying health disparities between a local farmworker population and the general population. This study of adult Sonoma County farmworkers found limited US-based health insurance coverage among farmworkers and disparities in health insurance status. Health insurance facilitates access to the medical system and safeguards against the cost of catastrophic illness (8). People with insurance are more likely to obtain health screenings, to receive care for chronic conditions, and to receive high-quality medical care and are less likely to have undiagnosed conditions (8-10). Among farmworkers especially, health insurance plays a critical role in the farmworker's decision to seek medical treatment (11).

The demographics and prevalence of the uninsured has changed since the Patient Protection and Affordable Care Act (PPACA) was passed in 2010; yet, health insurance options for undocumented immigrants are largely unchanged, because adult undocumented immigrants cannot enroll in Medicaid or Medicare and are ineligible for tax credits or subsidies (12). Immigration status was not measured in FHS, but data from the 2012 National Agricultural Workers Survey (NAWS) indicate that most California farmworkers are undocumented immigrants (13). Undocumented immigrant farmworkers may be the most likely to delay needed medical treatment (11), so more research is needed to explore the relationship between immigration status, low health insurance coverage, and use of health care among Sonoma County farmworkers. Most FHS participants were men, and men in Sonoma County are less likely to have health insurance than women (14). More research involving multivariable regression models is needed to determine if the disparity in health insurance was confounded by sex.

Although not significant at $P<.05$, our finding was that farmworkers who self-defined as working full-time for a farm grower or owner were more likely to have health insurance than were farmworkers who self-defined as working full-time for labor management companies or labor contractors. This result is supported by a study finding that farmworkers working for growers or owners were more willing to seek treatment of work-related injuries than were farmworkers working for labor contractors. It was hypothesized that farmworkers working for owners were provided employer-based health insurance while farmworkers working for contractors were not, leading to farmworkers employed by the owner being more willing to seek medical treatment (11). PPACA employer mandates require that employers of more than 50 employees provide health insurance (15); more research is needed to understand farmworker employer's compliance with this mandate.

\footnotetext{
The opinions expressed by authors contributing to this journal do not necessarily reflect the opinions of the U.S. Department of Health and Human Services, the Public Health Service, the Centers for Disease Control and Prevention, or the authors' affiliated institutions.
} 
Surveyed Sonoma County farmworkers were more than 3 times as likely to report poor or fair health in general as Sonoma County adults, suggesting health disparities between farmworkers and the general population. An individual's own appraisal of his or her general health status is a powerful predictor of future illness and death (16). We found that farmworkers reporting poor or fair health in general were significantly more likely to be obese or to have ever been diagnosed with high blood pressure or diabetes, suggesting that self-reported health is a good summary measure of health status among farmworkers.

Prevalence of overweight or obesity was significantly higher among farmworkers than among Sonoma County adults overall, a result consistent with CAWHS, which found that $79 \%$ of male farmworkers and $74 \%$ of female farmworkers were overweight or obese (5). Excess body weight has far-reaching implications for health, including increasing risk of type 2 diabetes mellitus, cardiovascular disease, cancer, and premature death (17). However, $21 \%$ of BMI data was missing from the FHS analysis, so these results require further research. This large percentage of missing BMI data also suggest that self-reported height and weight measurements may be an inaccurate method of gathering BMI data from farmworkers.

The prevalence of diabetes among farmworkers was 3 times higher than that among Sonoma County adults. Access to medical care, medications, and diabetes self-management education are critical to the care of diabetes and are necessary to improve patient outcomes (18). Uninsured adults with diabetes are mostly from lowincome racial/ethnic minority populations, and these individuals are less likely to access needed medical care for diabetes control (19-21). Given that farmworkers had a high prevalence of diabetes, most farmworkers were uninsured, and nearly all farmworkers had low incomes, the Sonoma County farmworker population should be prioritized for further diabetes research and prevention efforts. Undiagnosed diabetes is also most prevalent among the uninsured (20), suggesting that there may be farmworkers with undiagnosed diabetes in Sonoma County and that outreach efforts should include diabetes screening. Similarly, while no disparity in high blood pressure diagnosis was observed between Sonoma County farmworkers and the general population, more information is needed to determine if the lack of disparity was due to a high prevalence of undiagnosed high blood pressure among farmworkers.

Our results should be interpreted in the context of several limitations. This applied research study used nonrandom sampling of participant farmworkers, which may limit the generalizability of results. However, demographics of farmworkers in this report are similar to demographics of California farmworkers in the 2012
NAWS (13), suggesting that the FHS sample may be representative. The venue participation rate in FHS was low (62\%), which may also limit generalizability. Both labor management companies that were approached to participate declined, so the responses of farmworkers working for labor management companies may be underrepresented. Use of other methods for sampling farmworkers, such as household-based sampling, could increase the response rate of future studies. Immigration status was not directly asked in this study because of sensitivity of the topic. Self-reported health outcomes were not confirmed by health examinations. Sample sizes for the Sonoma County adult sample were too small to allow for comparison of farmworkers with Latino/Hispanic men in Sonoma County overall. This survey included only farmworkers that had completed any farm work in the previous 12 months, so farmworkers that were too ill to work during this timeframe were excluded, potentially making this sample of farmworkers healthier than the true farmworker population.

We found that farmworkers had significantly poorer health access and health outcomes than did Sonoma County adults overall. These findings have been widely disseminated to policy makers and stakeholders in an effort to raise awareness about disparities between farmworkers and the overall local population and to prioritize farmworkers for future health policies and interventions. Stakeholders have begun using these results to support funding efforts and to define the policies needed to address the disparities. It is hypothesized that most Sonoma County farmworkers are undocumented immigrants, so these undocumented farmworkers will be ineligible for expanded health insurance under PPACA. As such, health care access will remain a barrier to improving poor health status and reducing the burden of chronic disease. In California overall, political will for providing health care coverage to undocumented immigrants may be increasing. Senate Bill 4 provides Medicaid coverage to undocumented children aged less than 19 years starting in May 2016 (22), and this bill is a step toward eliminating poor access to health care among undocumented immigrant farmworkers in California. In Sonoma County, ongoing research aims to clearly describe the relationship between health insurance, health care access and use, and immigration status among adults. This research involves obtaining de-identified data from Sonoma County federally qualified health centers (FQHCs), which will be used to identify current health care use among undocumented immigrants at FQHCs and any disparities in use. Additionally, a survey of adult undocumented immigrants is being conducted with the goal of describing health care access and use and barriers to accessing health care in Sonoma County. Results from FHS and this research will be essential when developing policies to improve access to health care among undocumented adult immigrants, including farmworkers.

The opinions expressed by authors contributing to this journal do not necessarily reflect the opinions of the U.S. Department of Health and Human Services, the Public Health Service, the Centers for Disease Control and Prevention, or the authors' affiliated institutions. 


\section{Acknowledgments}

This publication was supported by cooperative agreement 1H75DP004611-01 from CDC. Its contents are solely the responsibility of the authors and do not necessarily represent the official views of $\mathrm{CDC}$.

We thank the farmworkers that participated in this survey for sharing their experiences and stories. Data collection and community engagement were coordinated by California Human Development Corporation, an organization committed to creating paths and opportunities for those seeking greater self-sufficiency, independence, and dignity through education, training, housing, and other services.

\section{Author Information}

Corresponding Author: Kristin L. Moore, MPH, Health Policy, Planning, and Evaluation Division, County of Sonoma Department of Health Services, 490 Mendocino Ave, Ste 101, Santa Rosa, CA 95401. Telephone: 707-565-6680. Email: kristinwhite16@gmail.com.

Author Affiliations: Jenny Mercado, Jana Hill, Sarah C. Katz, Health Policy, Planning, and Evaluation Division, County of Sonoma Department of Health Services, Santa Rosa, California.

\section{References}

1. Smedley BD, Stith AY, Nelson AR. Unequal treatment: confronting racial and ethnic disparities in health care (full printed version). Washington (DC): National Academies Press; 2003.

2. LaVeist TA. Minority populations and health: an introduction to health disparities in the United States. John Wiley \& Sons; 2005.

3. Satcher D, Higginbotham EJ. The public health approach to eliminating disparities in health. Am J Public Health 2008; 98(3):400-3.

4. The Secretary's Advisory Committee on National Health Promotion and Disease Prevention Objectives for 2020. Phase 1 report: Recommendations for the framework and format of Healthy People 2020. Section IV: Advisory Committee findings and recommendations. Washington (DC): US Department of Health and Human Services; 2008.

5. Villarejo D, McCurdy SA, Bade B, Samuels S, Lighthall D, Williams D 3d. The health of California's immigrant hired farmworkers. Am J Ind Med 2010;53(4):387-97.
6. California Health Interview Survey. CHIS. CHIS 2011-12 Adult Local Health Department File. Release 1 [computer file]. Los Angeles (CA): UCLA Center for Health Policy Research; August 2013.

7. Centers for Disease Control and Prevention. Defining adult overweight and obesity. http://www.cdc.gov/obesity/adult/ defining.html. Accessed February 12, 2014.

8. Wilper AP, Woolhandler S, Lasser KE, McCormick D, Bor DH, Himmelstein DU. Health insurance and mortality in US adults. Am J Public Health 2009;99(12):2289-95.

9. Ayanian JZ, Weissman JS, Schneider EC, Ginsburg JA, Zaslavsky AM. Unmet health needs of uninsured adults in the United States. JAMA 2000;284(16):2061-9.

10. Ayanian JZ, Zaslavsky AM, Weissman JS, Schneider EC, Ginsburg JA. Undiagnosed hypertension and hypercholesterolemia among uninsured and insured adults in the Third National Health and Nutrition Examination Survey. Am J Public Health 2003;93(12):2051-4.

11. Thierry AD, Snipes SA. Why do farmworkers delay treatment after debilitating injuries? Thematic analysis explains if, when, and why farmworkers were treated for injuries. Am J Ind Med 2015;58(2):178-92.

12. Sommers BD. Stuck between health and immigration reform - care for undocumented immigrants. N Engl J Med 2013; 369(7):593-5.

13. National Agricultural Workers Survey. NAWS public access data file 2014. Washington (DC): US Department of Labor; 2014.

14. US Census Bureau. American Community Survey; 2013. http:/ /factfinder.census.gov/faces/tableservices/jsf/pages/ productview.xhtml?pid=ACS_14_5YR_S2702\&prodType=tab le. Accessed November 23, 2015.

15. Patient Protection and Affordable Care Act, 42 U.S.C. $\$ 18001$ (2010).

16. Eriksson I, Undén A-L, Elofsson S. Self-rated health. Comparisons between three different measures. Results from a population study. Int J Epidemiol 2001;30(2):326-33.

17. Malik VS, Popkin BM, Bray GA, Després J-P, Hu FB. Sugarsweetened beverages, obesity, type 2 diabetes mellitus, and cardiovascular disease risk. Circulation 2010; 121(11):1356-64.

18. Funnell MM, Brown TL, Childs BP, Haas LB, Hosey GM, Jensen B, et al. National Standards for diabetes selfmanagement education. Diabetes Care 2011;34(Suppl 1):S89-96.

19. Nelson KM, Chapko MK, Reiber G, Boyko EJ. The association between health insurance coverage and diabetes care; data from the 2000 Behavioral Risk Factor Surveillance System. Health Serv Res 2005;40(2):361-72.

The opinions expressed by authors contributing to this journal do not necessarily reflect the opinions of the U.S. Department of Health and Human Services, the Public Health Service, the Centers for Disease Control and Prevention, or the authors' affiliated institutions. 
20. Wilper AP, Woolhandler S, Lasser KE, McCormick D, Bor DH, Himmelstein DU. Hypertension, diabetes, and elevated cholesterol among insured and uninsured U.S. adults. Health Aff (Millwood) 2009;28(6):w1151-9.

21. Wilper AP, Woolhandler S, Lasser KE, McCormick D, Bor DH, Himmelstein DU. A national study of chronic disease prevalence and access to care in uninsured U.S. adults. Ann Intern Med 2008;149(3):170-6.

22. California Legislative Counsel. SB4: Health care coverage: immigration status. §14007.8 (2015). 


\section{Tables}

Table 1. Demographic Characteristics of Surveyed Adult Farmworkers $(n=293)$, Sonoma County Farmworker Health Survey, 2013-2014

\begin{tabular}{|c|c|}
\hline Characteristic $^{a}$ & $\mathrm{n}(\%)^{\mathrm{b}}$ \\
\hline \multicolumn{2}{|l|}{ Sex } \\
\hline Male & 267 (91.1) \\
\hline Female & $26(8.9)$ \\
\hline Median (minimum-maximum) age, $y$ & $37(18-75)$ \\
\hline \multicolumn{2}{|l|}{ Age group, y } \\
\hline $18-24$ & $39(13.6)$ \\
\hline $25-34$ & 89 (31.0) \\
\hline $35-44$ & $69(24.0)$ \\
\hline $45-54$ & $51(17.8)$ \\
\hline$\geq 55$ & $39(13.6)$ \\
\hline \multicolumn{2}{|l|}{ Latino or Hispanic ancestry } \\
\hline Latino or Hispanic & $272(95.4)$ \\
\hline Non-Latino or non-Hispanic & $13(4.6)$ \\
\hline \multicolumn{2}{|l|}{ Region of ancestry } \\
\hline Mexican & $250(89.9)$ \\
\hline Mexican American & $15(5.4)$ \\
\hline Central American & $8(2.9)$ \\
\hline Other & $5(1.8)$ \\
\hline \multicolumn{2}{|l|}{ Total family income in $2012, \$$} \\
\hline$\leq 9,999$ & $26(9.4)$ \\
\hline $10,000-19,999$ & $49(17.6)$ \\
\hline $20,000-29,999$ & $73(26.3)$ \\
\hline$\geq 30,000$ & $34(12.2)$ \\
\hline Don't remember & $96(34.5)$ \\
\hline \multicolumn{2}{|l|}{ Highest educational attainment } \\
\hline 8th grade or less & $150(54.0)$ \\
\hline 9th grade through high school graduate or equivalent & $117(42.1)$ \\
\hline More than high school graduate & $11(4.0)$ \\
\hline \multicolumn{2}{|l|}{ English speaking ability } \\
\hline Not at all or a little & $208(73.0)$ \\
\hline Somewhat, well, or very well & $77(27.0)$ \\
\hline
\end{tabular}

${ }^{a}$ Unless otherwise specified, data are presented as $\mathrm{n}(\%)$.

${ }^{b}$ Estimates with less than $10 \%$ missing responses were included in analysis. Because of missing values, denominators may not add up to 293 for each variable.

Percentages may not add up to $100 \%$ because of rounding. 
(continued)

Table 1. Demographic Characteristics of Surveyed Adult Farmworkers $(n=293)$, Sonoma County Farmworker Health Survey, 2013-2014

\begin{tabular}{|c|c|}
\hline Characteristic $^{a}$ & $n(\%)^{b}$ \\
\hline \multicolumn{2}{|l|}{ Farmworker family structure } \\
\hline Single & $94(32.5)$ \\
\hline Married/living with partner & $70(24.2)$ \\
\hline Married/living with partner and child(ren) & $125(43.3)$ \\
\hline \multicolumn{2}{|l|}{ Permanent resident of Sonoma County } \\
\hline Yes & $250(88.3)$ \\
\hline No & $33(11.6)$ \\
\hline \multicolumn{2}{|l|}{ Crop } \\
\hline Grapes & $268(91.5)$ \\
\hline Other crops, not grapes & $25(8.5)$ \\
\hline \multicolumn{2}{|l|}{ Category of farmworker } \\
\hline Full-time farmworker working for owner or grower & $123(42.1)$ \\
\hline $\begin{array}{l}\text { Full-time farmworker working for contractor or labor management company or farmworker didn't know who } \\
\text { boss was }\end{array}$ & $95(32.5)$ \\
\hline Part-time or seasonal farmworker & $74(25.3)$ \\
\hline
\end{tabular}

${ }^{a}$ Unless otherwise specified, data are presented as $\mathrm{n}(\%)$.

${ }^{b}$ Estimates with less than $10 \%$ missing responses were included in analysis. Because of missing values, denominators may not add up to 293 for each variable.

Percentages may not add up to $100 \%$ because of rounding. 
Table 2. Age-Adjusted Prevalence of US-Based Health Insurance and Health Characteristics Among Surveyed Adult Sonoma County Farmworkers $(n=293), 2013-2014$, and Adults Overall in Sonoma County, 2011-2012

\begin{tabular}{|c|c|c|c|c|c|}
\hline \multirow[b]{2}{*}{ Status } & \multicolumn{2}{|c|}{ Sonoma County Farmworkers ${ }^{a}$} & \multicolumn{2}{|c|}{ Sonoma County Adults ${ }^{b}$} & \multirow[b]{2}{*}{$P$ Value } \\
\hline & $\mathrm{n}$ & Age-Adjusted \% $(95 \% \mathrm{CI})^{\mathrm{C}}$ & Weighted $n$ & $\%(95 \% \mathrm{Cl})$ & \\
\hline Health insurance & 81 & $29.6(23.2-36.1)$ & 53,000 & $85.7(81.1-90.4)$ & $<.001$ \\
\hline Self-rated general health as poor or fair ${ }^{d}$ & 115 & $43.9(35.9-51.9)$ & 49,000 & $13.1(9.4-16.8)$ & $<.001$ \\
\hline Overweight or obese $\mathrm{e}^{\mathrm{e}}$ & 201 & $93.8(80.8-106.7)$ & 80,000 & $54.3(48.4-60.3)$ & $<.001$ \\
\hline Ever diagnosed with diabetes & 23 & $14.5(8.6-20.4)$ & 19,000 & $5.2(3.0-7.4)$ & .002 \\
\hline Ever diagnosed with high blood pressure & 49 & $26.0(18.6-33.3)$ & 93,000 & $24.8(20.2-29.3)$ & .75 \\
\hline
\end{tabular}

Abbreviation: $\mathrm{Cl}$, confidence interval.

${ }^{a}$ Data from Sonoma County Farmworkers Health Survey 2013-2014.

${ }^{\mathrm{b}}$ Data from Sonoma County adult California Health Interview Survey 2011-2012.

${ }^{\mathrm{c}}$ Indirect standardization to California Health Interview Survey population was used to develop age-adjusted prevalence.

${ }^{\mathrm{d}}$ Farmworkers were asked to rate their health in general as excellent, very good, good, fair, or poor.

${ }^{\mathrm{e}}$ Overweight or obese was defined as a body mass index (BMI) of $25.0 \mathrm{~kg} / \mathrm{m}^{2}$ or more based on self-reported height and weight. Data on height and weight were missing for $21 \%$ of respondents, so estimates should be interpreted with caution. 
Table 3. US-Based Health Insurance Status and Self-Reported General Health by Selected Demographics and Health Outcomes, Sonoma County Farmworker Health Survey $(n=293), 2013-2014$

\begin{tabular}{|c|c|c|c|c|c|c|}
\hline \multirow[b]{2}{*}{ Characteristic } & \multicolumn{3}{|c|}{ Health Insurance Status } & \multicolumn{3}{|c|}{ Self-Rated Health Status ${ }^{a}$} \\
\hline & $\begin{array}{c}\text { No Health Insurance, } \\
n(\text { Row \%) }\end{array}$ & $\begin{array}{c}\text { Health Insurance, } \\
\text { n (Row \%) }\end{array}$ & $P$ Value $^{\mathrm{c}}$ & $\begin{array}{l}\text { Poor or Fair, } \\
\text { n (Row \%) }\end{array}$ & $\begin{array}{l}\text { Excellent, Very Good, } \\
\text { or Good, } \mathrm{n} \text { (Row \%) }\end{array}$ & $P$ Value $^{\mathrm{c}}$ \\
\hline Total $^{d}$ & $206(71.5)$ & $82(28.5)$ & NA & $117(40.2)$ & $174(59.8)$ & NA \\
\hline \multicolumn{7}{|l|}{ Sex } \\
\hline Male & $194(74.1)$ & $68(26.0)$ & \multirow{2}{*}{.003} & $104(39.3)$ & $161(60.8)$ & \multirow{2}{*}{.29} \\
\hline Female & $12(46.2)$ & $14(53.9)$ & & $13(50.0)$ & $13(50.0)$ & \\
\hline \multicolumn{7}{|l|}{ Age, y } \\
\hline $18-24$ & $26(66.7)$ & $13(33.3)$ & \multirow{5}{*}{.06} & $13(33.3)$ & $26(66.7)$ & \multirow{5}{*}{.002} \\
\hline $25-34$ & $73(83.0)$ & $15(17.1)$ & & $24(27.3)$ & $64(72.7)$ & \\
\hline $35-44$ & $46(67.7)$ & $22(32.4)$ & & $34(49.3)$ & $35(50.7)$ & \\
\hline $45-54$ & $31(62.0)$ & $19(38.0)$ & & $20(39.2)$ & $31(60.8)$ & \\
\hline$\geq 55$ & $25(67.6)$ & $12(32.4)$ & & $24(61.5)$ & $15(38.5)$ & \\
\hline \multicolumn{7}{|c|}{ Total family income in 2012, \$ } \\
\hline$\leq 9,999$ & $15(65.2)$ & $8(34.8)$ & \multirow{5}{*}{.11} & $14(53.9)$ & $12(46.2)$ & \multirow{5}{*}{.33} \\
\hline $10,000-19,999$ & 39 (79.6) & $10(20.4)$ & & $19(38.8)$ & $30(61.2)$ & \\
\hline $20,000-29,999$ & 55 (75.3) & $18(24.7)$ & & 26 (35.6) & $47(64.4)$ & \\
\hline$\geq 30,000$ & 19 (55.9) & $15(44.1)$ & & $11(33.3)$ & $22(66.7)$ & \\
\hline Don't remember & $73(76.0)$ & $23(24.0)$ & & $44(46.3)$ & $51(53.7)$ & \\
\hline \multicolumn{7}{|c|}{ Highest educational attainment } \\
\hline 8th grade or less & $112(76.2)$ & $35(23.8)$ & \multirow{2}{*}{.048} & $63(42.3)$ & $86(57.7)$ & \multirow{2}{*}{.62} \\
\hline 9th grade or more & $83(65.4)$ & $44(34.7)$ & & $50(39.4)$ & $77(60.6)$ & \\
\hline \multicolumn{7}{|c|}{ Farmworker family structure } \\
\hline Single & $73(80.2)$ & $18(19.8)$ & \multirow{3}{*}{.03} & $36(38.3)$ & $58(61.7)$ & \multirow{3}{*}{.92} \\
\hline $\begin{array}{l}\text { Married/living with } \\
\text { partner }\end{array}$ & $51(75.0)$ & $17(25.0)$ & & $28(40.0)$ & $42(60.0)$ & \\
\hline $\begin{array}{l}\text { Married/living with } \\
\text { partner and child(ren) }\end{array}$ & $80(64.0)$ & $45(36.0)$ & & $51(41.1)$ & $73(58.9)$ & \\
\hline \multicolumn{7}{|c|}{ Permanent resident of Sonoma County } \\
\hline No & $24(75.0)$ & $8(25.0)$ & \multirow{2}{*}{.56} & $12(36.4)$ & $21(63.6)$ & \multirow{2}{*}{.63} \\
\hline Yes & $173(70.0)$ & $74(30.0)$ & & $102(40.8)$ & $148(59.2)$ & \\
\hline
\end{tabular}

\section{Category of farmworker}

Abbreviation: NA, not applicable.

a Self-rated general health as excellent, very good, good, fair, or poor.

${ }^{\mathrm{b}}$ Row $\%$ = row percentages shown. Percentages might not add to 100 because of rounding.

${ }^{c} x^{2} P$ value.

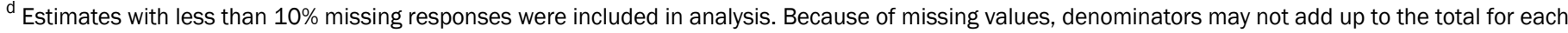
column.

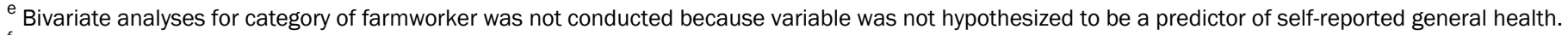

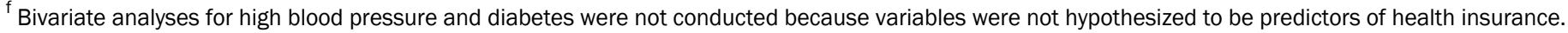


(continued)

Table 3. US-Based Health Insurance Status and Self-Reported General Health by Selected Demographics and Health Outcomes, Sonoma County Farmworker Health Survey $(n=293), 2013-2014$

\begin{tabular}{|c|c|c|c|c|c|c|}
\hline \multirow[b]{2}{*}{ Characteristic } & \multicolumn{3}{|c|}{ Health Insurance Status } & \multicolumn{3}{|c|}{ Self-Rated Health Status ${ }^{a}$} \\
\hline & $\begin{array}{c}\text { No Health Insurance, } \\
\text { n (Row \%) }\end{array}$ & $\begin{array}{l}\text { Health Insurance, } \\
\text { n (Row \%) }\end{array}$ & $P$ Value $^{\mathrm{c}}$ & $\begin{array}{l}\text { Poor or Fair, } \\
\text { n (Row \%) }\end{array}$ & $\begin{array}{l}\text { Excellent, Very Good, } \\
\text { or Good, } \mathrm{n} \text { (Row \%) }\end{array}$ & $P$ Value $^{\mathrm{c}}$ \\
\hline $\begin{array}{l}\text { Full-time farmworker } \\
\text { working for owner or } \\
\text { grower }\end{array}$ & $79(64.8)$ & $43(35.3)$ & \multirow{3}{*}{.07} & & & \multirow{3}{*}{-} \\
\hline $\begin{array}{l}\text { Full-time farmworker } \\
\text { working for contractor } \\
\text { or labor management } \\
\text { company or } \\
\text { farmworker didn't } \\
\text { know who boss was }\end{array}$ & $70(76.1)$ & $22(23.9)$ & & & & \\
\hline $\begin{array}{l}\text { Part-time or seasonal } \\
\text { farmworker }\end{array}$ & $57(78.1)$ & $16(21.9)$ & & & & \\
\hline \multicolumn{7}{|c|}{ Ever been diagnosed with high blood pressure } \\
\hline No & & & \multirow{2}{*}{$-^{f}$} & $75(31.4)$ & $164(68.6)$ & \multirow{2}{*}{$<.001$} \\
\hline Yes & & & & $39(79.6)$ & $10(20.4)$ & \\
\hline \multicolumn{7}{|c|}{ Ever been diagnosed with diabetes } \\
\hline No & & & \multirow{2}{*}{$-^{f}$} & $96(36.6)$ & $166(63.4)$ & \multirow{2}{*}{.001} \\
\hline Yes & & & & $18(72.0)$ & $7(28.0)$ & \\
\hline
\end{tabular}

Abbreviation: NA, not applicable.

a Self-rated general health as excellent, very good, good, fair, or poor.

${ }^{\mathrm{b}}$ Row $\%=$ row percentages shown. Percentages might not add to 100 because of rounding.

${ }^{c} x^{2} P$ value.

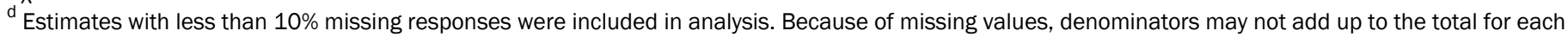
column.

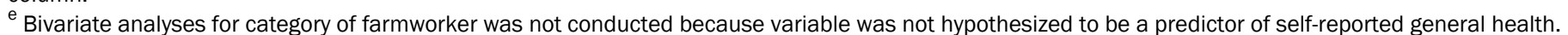

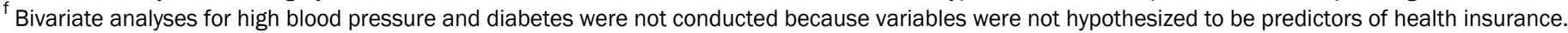

